\title{
The Relationship between Beliefs in Cooperation, Motivation, and Engagement in Cooperative Learning
}

\author{
Takatoyo Umemoto ${ }^{1}$, Naoya Yada ${ }^{2}$ \\ ${ }^{1}$ Faculty of Humanities, Kyushu Women's University, Kitakyushu, Japan \\ ${ }^{2}$ Graduate School of Literature and Human Sciences, Osaka City University, Osaka, Japan \\ Email: t-umemoto@kwuc.ac.jp
}

How to cite this paper: Umemoto, T., \& Yada, N. (2016). The Relationship between Beliefs in Cooperation, Motivation, and Engagement in Cooperative Learning. Psychology, 7, 1335-1341.

http://dx.doi.org/10.4236/psych.2016.710135

Received: August 10, 2016

Accepted: September 19, 2016

Published: September 22, 2016

Copyright $\odot 2016$ by authors and Scientific Research Publishing Inc. This work is licensed under the Creative Commons Attribution International License (CC BY 4.0).

http://creativecommons.org/licenses/by/4.0/ (c) (i) Open Access

\begin{abstract}
This study examined the relationship between beliefs in cooperation, motivation and engagement in cooperative learning. Beliefs in cooperation have three subscales: usefulness of cooperation, individual orientation and inequity. Self-reported questionnaire was administered to 181 undergraduate students at two universities. The results of path analysis indicated that usefulness of cooperation positively predicted self-efficacy and intrinsic value. Moreover, self-efficacy and intrinsic value positively predicted behavioral engagement, and intrinsic value positively predicted emotional engagement. On the other hand, individual orientation negatively predicted intrinsic value and inequity did not predict any motivational factors. The effects of beliefs in cooperation on cooperative learning process were discussed in light of the current findings.
\end{abstract}

\section{Keywords}

Cooperative Learning, Beliefs in Cooperation, Motivation, Engagement

\section{Introduction}

In recent years, "active learning" in classrooms has been encouraged by Ministry of Education, Culture, Sports, Science and Technology in Japan, and a focus on cooperative learning is fast gaining importance. In cooperative learning, students work together to maximize their own and each other's learning in small groups (Johnson, Johnson, \& Smith, 1991). Many researchers have examined the process of cooperative learning in Japan (e.g., Machi \& Nakaya, 2014). To examine the cooperative learning process, it is important to take into account "how learners think of cooperation". For example, there 
is some possibility that students who perceive cooperative learning as positive show better performances than students who perceive it as negative. Nagahama, Yasunaga, Sekita, \& Kouhara (2009) developed a scale that measured Japanese undergraduate students' belief in cooperation in the cooperative learning process and revealed a scale with three subscale factors. First, usefulness of cooperation represented a belief concerning usefulness of cooperation in cooperative learning. Second, individual orientation described a belief concerning the tendency to learn individually and avoid learning with friends. Third, inequity represented the belief that benefits from cooperative learning varied from person to person. Although it is necessary to examine how these beliefs influence the cooperative learning process to promote it effectively in classrooms, only a few researches have examined the effects of beliefs in cooperation on learning behavior in co-operative learning.

The purpose of this study was to examine the relationship between beliefs in cooperation, motivation and learning behavior in cooperative learning by using a path analysis. In the path model, we assumed that motivation mediated the relationship between beliefs in cooperation and learning behavior. Students with positive beliefs about cooperation appeared to display a high motivation for cooperative learning, while students with negative beliefs about cooperation showed a low motivation toward the cooperative learning process. Motivation is an important factor that influences learning behavior (Pintrich, 1999; Zimmerman \& Schunk, 2011). We focused on expectancy-value theory, which is one of the most famous theories explaining motivational processes in learning (Eccles \& Wigfield, 2002). In this theory, students perceived that expectancy and value led to motivation in learning. In this study, self-efficacy was selected as expectancy factor, and intrinsic value was selected as value factor. Self-efficacy is the conviction that learner can successfully execute the behavior required to produce the outcome (Bandura, 1977). Intrinsic value refers to learners' reasons for doing a task including intrinsic interest and perceived importance of learning contents (Pintrich \& De Groot, 1990). Since previous studies have shown that self-efficacy and intrinsic value have positive effects on learning behavior in individualistic learning (e.g., Wolters \& Pintrich, 1998), these variables also had positive effects on cooperative learning process.

Engagement was selected as learning behavior in this study. Engagement refers to the quality of a student's connection or involvement with the endeavor of schooling (Christenson, Reschly, \& Wylie, 2012; Fredricks, Blumenfeld, \& Paris, 2004). Since emotional aspect of learning has been gaining attention in recent years (e.g., Pekrun \& LinnenbrinkGarcia, 2014), we measured emotional engagement in addition to behavioral engagement. Behavioral engagement refers to an on-task behavior, academic behavior and class participation, while emotional engagement reflects an energized emotional state, such as enthusiasm, interest and enjoyment (Skinner, Kindermann, \& Furrer, 2009).

\section{Methods}

\subsection{Participants and Procedure}

The self-report questionnaire survey was administered to 181 Japanese undergraduate 
students at two universities in June 2016. Samples of analysis were 173 undergraduate students who had experienced cooperative learning in school (72 freshmen, 47 sophomores, 45 juniors, 8 seniors, and 1 unknown; Mean age $=19.36, S D=1.22$; 44 male, and 129 female). The questionnaire was distributed to undergraduates attending a psychology class at each university. Undergraduates were asked to complete the questionnaires, and these were collected on the spot by the authors.

\subsection{Measures}

Belief in cooperation was assessed by the scale (18 items) of Nagahama, Yasunaga, Sekita, \& Kouhara (2009). The scale consisted of three subscales, i.e., usefulness of cooperation (9 items), individual orientation (6 items), and inequity (3 items). An example of items of usefulness of cooperation scale was "I think I can get good results if I work in cooperation with others rather than individually". An example of items of individual orientation scale was "I can't do what I want to do when I do something with others". An example of items of inequity scale was "It is not necessary for a gifted person to work in cooperation with others".

The self-efficacy scale by Nakanishi (2004) was used. Expression of each item was slightly modified for measuring self-efficacy in cooperative learning. The scale consisted of six items and an example of items was "I believe that I can solve the problems and the tasks in cooperative learning". Moreover, the Japanese translated version of intrinsic value scale (Ito, 1996) by Pintrich \& De Groot (1990) was used. Expression of items was slightly modified for measuring intrinsic value in cooperative learning. The scale consisted of six items, and an example of items was "It is important for me to learn what is being taught in cooperative learning".

The Japanese translated version of behavioral engagement scale (Umemoto \& Tanaka, 2012) by Skinner et al. (2009) was used. Expression of items was slightly modified for measuring behavioral engagement in cooperative learning. The scale consisted of five items, and an example of items was "I try hard to do well in cooperative learning". The Japanese translated version of emotional engagement scale (Umemoto, Ito, \& Tanaka, In Press) by Skinner et al. (2009) was used. Expression of items was slightly modified for measuring emotional engagement in cooperative learning. The scale consisted of five items, and an example of items was "When I work on something in cooperative learning, I get involved".

All items were answered on a five-point scale ranging from 1 (not true at all) to 5 (considerably true).

\subsection{Consideration of Human Rights}

In this study, human rights of participants were considered as follows. The following statements were printed clearly on the face sheet of the questionnaire: "there is no right or wrong answer," "if you do not want to answer some questions, please skip these," "because survey answers are analyzed statistically, each personal answer is not identified," and "the author disposes of all questionnaires responsibly". 


\section{Results}

\subsection{Preliminary Analysis}

Following previous work, scores for each subscale (beliefs in cooperation, self-efficacy, intrinsic value, and two engagements) were computed. Omega coefficients for all subscales were moderately high. Therefore, average scores were calculated for each subscale. Table 1 shows means, SDs, and omega coefficients for each subscale, and Table 2 shows the results of the correlation analysis. Table 1 indicated that the mean of usefulness of cooperation was moderately high, and the mean of inequity was low. Table 2 indicated that usefulness of cooperation was related to motivational factors and two engagements positively. On the other hand, individual orientation and inequity related to these subscales negatively.

\subsection{Path Analysis}

To examine how belief in cooperation and motivational factors related to engagement in cooperative learning, path analysis by structural equation modeling was conducted (Figure 1). Covariance among three subscales of beliefs in cooperation was assumed. Moreover, path from emotional engagement to behavioral engagement was also assumed

Table 1. Descriptive statistics of each subscale.

\begin{tabular}{cccc}
\hline Subscale & Mean & $S D$ & $\omega$ \\
\hline Usefulness of cooperation & 3.80 & 0.53 & 0.87 \\
Individual orientation & 3.22 & 0.65 & 0.82 \\
Inequity & 2.06 & 0.72 & 0.89 \\
Self-efficacy & 3.66 & 0.67 & 0.93 \\
Intrinsic value & 3.50 & 0.74 & 0.93 \\
Behavioral engagement & 3.71 & 0.64 & 0.91 \\
Emotional engagement & 3.18 & 0.88 & 0.95 \\
\hline
\end{tabular}

Table 2. The results of correlation analysis.

\begin{tabular}{ccccccc}
\hline Subscale & $\begin{array}{c}\text { Individual } \\
\text { orientation }\end{array}$ & Inequity & Self-efficacy & $\begin{array}{c}\text { Intrinsic } \\
\text { value }\end{array}$ & $\begin{array}{c}\text { Behavioral } \\
\text { engagement }\end{array}$ & $\begin{array}{c}\text { Emotional } \\
\text { engagement }\end{array}$ \\
\hline Usefulness of cooperation & $-0.37^{* * *}$ & $-0.38^{* * *}$ & $0.66^{* * *}$ & $0.72^{* * *}$ & $0.56^{* * *}$ & $0.56^{* * *}$ \\
Individual orientation & & $0.37^{* * *}$ & $-0.34^{* * *}$ & $-0.48^{* * *}$ & $-0.35^{* * *}$ & $-0.53^{* * *}$ \\
Inequity & & $-0.32^{* * *}$ & $-0.39^{* * *}$ & $-0.37^{* * *}$ & $-0.26^{* * *}$ \\
Self-efficacy & & & $0.68^{* * *}$ & $0.56^{* * *}$ & $0.57^{* * *}$ \\
Intrinsic value & & & & $0.61^{* * *}$ & $0.78^{* * *}$ \\
Behavioral engagement & & & & & $0.59^{* * *}$ \\
\hline
\end{tabular}

${ }^{* * *} p<0.001 ;$ Note: The range of sample size in the correlational analysis was $172-169$. 


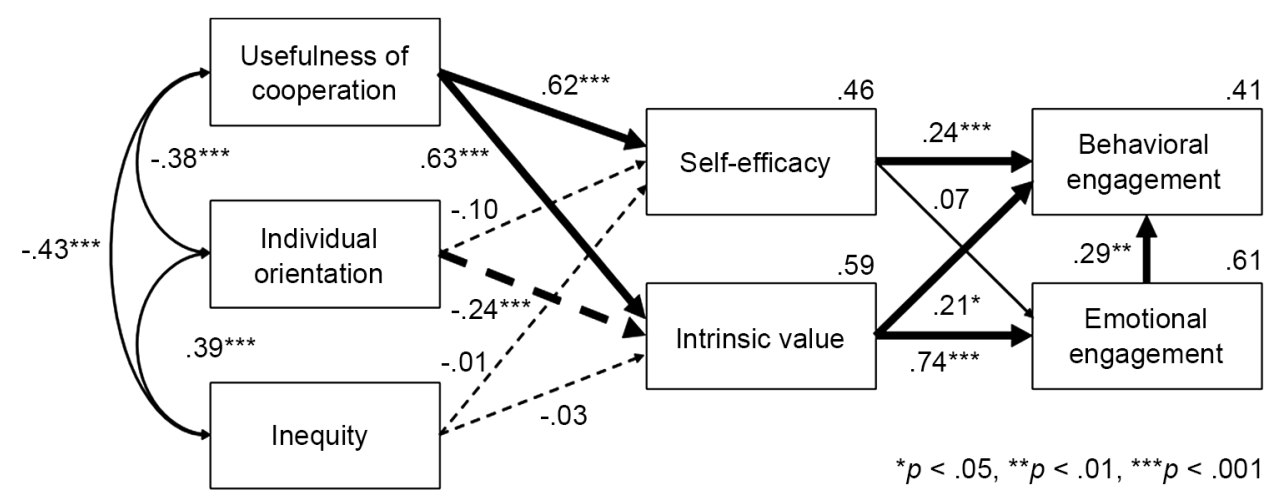

Figure 1. The result of path analysis.

because a pervious study had showed the positive effects of emotional engagement on behavioral engagement (Umemoto et al., In Press). Fit indexes of the path model were $\chi^{2}(10)=48.18(p<0.001)$, CFI $=0.94$, RMSEA $=0.15$, SRMR $=0.06$. The results indicated that usefulness of cooperation positively predicted self-efficacy and intrinsic value. Moreover, self-efficacy and intrinsic value positively predicted behavioral engagement, and intrinsic value positively predicted emotional engagement. On the other hand, individual orientation negatively predicted intrinsic value, and inequity did not predict any motivational factors.

\section{Discussion}

The purpose of this study is examining the relationship between beliefs in cooperative, motivation and two engagements in cooperative learning by using a path analysis.

\subsection{Relationship between Beliefs in Cooperative, Motivation and Two Engagements in Cooperative Learning}

Usefulness of cooperation positively predicted self-efficacy and intrinsic value because students who perceived learning with others as useful were more likely to successfully achieve tasks in cooperative learning. Moreover, they tended to be more confident of their own abilities. Previous achievement is one of the important factors promoting self-efficacy (Bandura, 1977). Moreover, students who had positive beliefs in cooperative learning were more likely to place a positive value (i.e., interest and importance) on tasks in cooperative learning. Next, self-efficacy and intrinsic value positively predicted behavioral engagement, and intrinsic value positively predicted emotional engagement. According to beta coefficients in Figure 1, self-efficacy mainly had positive effects on behavioral aspect, and intrinsic value primarily had positive effects on the emotional aspect of cooperative learning. These positive effects were consistent with the results of previous studies that examined the individualistic learning process (e.g., Pintrich \& De Groot, 1990; Wolters \& Pintrich, 1998). Because self-efficacy influences persistence in learning and performance positively (Eccles \& Wigfield, 2002), students who had more confidence in their own ability in cooperative learning were more likely to engage in tasks actively and show better performance, such as high efforts and concentration in 
cooperative learning. Students who placed a high-perceived value on tasks in cooperative learning were more likely to show active engagement with regard to emotional aspects, such as enjoyment and enthusiasm. Intrinsic value is also an important factor for improving behavioral engagement because it has positive effects on behavioral engagement directly and indirectly via emotional engagement. Since emotion has a motivational aspect that influences behavior (Pekrun, Eliot, \& Maier, 2009), emotional engagement had a positive influence on behavioral engagement in the path model. These results indicate that there is a possibility of teachers promoting active cooperative learning by intervening and enhancing usefulness of cooperation that has positive effects on learning engagements via motivational factors.

On the other hand, individual orientation negatively predicted intrinsic value. This result indicated that students who preferred individualistic learning and avoided cooperation with others seemed to have no interest in tasks that involved cooperative learning. The finding that such students are not likely to perceive tasks in cooperative learning as valuable needs to be examined in future study. Inequity did not show any effects on motivational factors. Inequity is a relatively negative belief in cooperation similar to individual orientation belief. Although inequity correlated to motivational factors negatively in the correlational analysis, these correlations disappeared once the effect of individual orientation in path analysis was controlled. More studies are needed to examine the role of inequity in cooperative learning.

\subsection{Limitations and Perspectives}

Limitations of this study and future perspectives are shown below. The causal relationships among variables are still unclear because the results of this study are based on cross-sectional data. Longitudinal survey needs to be conducted to discover the causal relationships among these variables. Moreover, intervention studies for promoting usefulness of cooperation are required.

\section{Acknowledgements}

We gratefully acknowledge the cooperation of undergraduate students participated in our research.

\section{References}

Bandura, A. (1977). Self-Efficacy: Toward a Unifying Theory of Behavioral Change. Psychological Review, 84, 191-215. http://dx.doi.org/10.1037/0033-295X.84.2.191

Christenson, S. L., Reschly, A. L., \& Wylie, C. (2012). Handbook of Research on Student Engagement. New York: Springer.

Eccles, J. S., \& Wigfield, A. (2002). Motivational Beliefs, Values, and Goals. Annual Review of Psychology, 53, 109-132. http://dx.doi.org/10.1146/annurev.psych.53.100901.135153

Fredricks, J. A., Blumenfeld, P. C., \& Paris, A. H. (2004). School Engagement: Potential of the Concept, State of the Evidence. Review of Educational Research, 74, 59-109. http://dx.doi.org/10.3102/00346543074001059

Ito, T. (1996). Self-Efficacy, Causal Attribution and Learning Strategy in an Academic Achieve- 
ment Situation. Japanese Journal of Educational Psychology, 44, 340-349.

http://dx.doi.org/10.5926/jjep1953.44.3_340

Johnson, D. W., Johnson, R. T., \& Smith, K. A. (1991). Cooperative Learning: Increasing College Faculty Instructional Productivity. ASHE-ERIC Higher Education Report, No.4. Washington DC: School of Education and Human Development, The George Washington University.

Machi, T., \& Nakaya, M. (2014). Reciprocal Teaching Intervention in Elementary Mathematics Classrooms: Children's Social Goals, Interactive Processes, and Academic Achievement. Japanese Journal of Educational Psychology, 62, 322-335. http://dx.doi.org/10.5926/jjep.62.322

Nagahama, F., Yasunaga, S., Sekita, K., \& Kouhara, S. (2009). Development of a Scale to Measure Belief in Cooperation. Japanese Journal of Educational Psychology, 57, 24-37. http://dx.doi.org/10.5926/jjep.57.24

Nakanishi, Y. (2004). Effects of Strategy Attribution for Success/Failure on Self-Efficacy. Japanese Journal of Educational Psychology, 52, 127-138. http://dx.doi.org/10.5926/jiep1953.52.2_127

Pekrun, R., Elliot, A. J., \& Maier, M. A. (2009). Achievement Goals and Achievement Emotions: Testing a Model of Their Joint Relations with Academic Performance. Journal of Educational Psychology, 101, 115-135. http://dx.doi.org/10.1037/a0013383

Pekrun, R., \& Linnenbrink-Garcia, L. (2014). International Handbook of Emotion in Education. New York: Routledge.

Pintrich, P. R. (1999). The Role of Motivation in Promoting and Sustaining Self-Regulated Learning. International Journal of Educational Research, 31, 459-470. http://dx.doi.org/10.1016/S0883-0355(99)00015-4

Pintrich, P. R., \& De Groot, E. V. (1990). Motivational and Self-Regulated Learning Components of Classroom Academic Performance. Journal of Educational Psychology, 82, 33-40. http://dx.doi.org/10.1037/0022-0663.82.1.33

Skinner, E. A., Kindermann, T. A., \& Furrer, C. J. (2009). A Motivational Perspective on Engagement and Disaffection: Conceptualization and Assessment of Children's Behavioral and Emotional Participation in Academic Activities in the Classroom. Educational and Psychological Measurement, 69, 493-525. http://dx.doi.org/10.1177/0013164408323233

Umemoto, T., Ito, T., \& Tanaka, K. (In Press) Relationships between Regulation Strategies, Emotional and Behavioral Engagement, and Academic Achievement. Japanese Journal of Psychology.

Umemoto, T., \& Tanaka, K. (2012). Motivational Regulation Strategies in Undergraduates. Japanese Journal of Personality, 21, 138-151. http://dx.doi.org/10.2132/personality.21.138

Wolters, C. A., \& Pintrich, P. R. (1998). Contextual Differences in Student Motivation and Self-Regulated Learning in Mathematics, English, and Social Studies Classrooms. Instructional Science, 26, 27-47. http://dx.doi.org/10.1007/978-94-017-2243-8_6

Zimmerman, B. J., \& Schunk, D. H. (2011). Handbook of Self-Regulation of Learning and Performance. New York: Routledge. 
Submit or recommend next manuscript to SCIRP and we will provide best service for you:

Accepting pre-submission inquiries through Email, Facebook, LinkedIn, Twitter, etc. A wide selection of journals (inclusive of 9 subjects, more than 200 journals)

Providing 24-hour high-quality service

User-friendly online submission system

Fair and swift peer-review system

Efficient typesetting and proofreading procedure

Display of the result of downloads and visits, as well as the number of cited articles

Maximum dissemination of your research work

Submit your manuscript at: http://papersubmission.scirp.org/

Or contact psych@scirp.org 